\title{
Los espacios para la exhibición de cine en Bogotá: un análisis urbano.
}

\author{
Alfredo Montaño \\ José David Pinzón
}

La historia de la exhibición se considera un campo prioritario de investigación dentro de la historiografía del cine y de la ciudad pues sintetiza dimensiones económicas, tecnológicas y sociales, “...esta prioridad está justificada por la ausencia de trabajos de este tipo para muchas ciudades y poblados colombianos, a lo que suma el reconocimiento de que mientras la exhibición en el país ha sido continua y de gran relevancia económica, social y cultural, la producción cinematográfica nacional ha sido intermitente, no ha desarrollado una industria y ha sido, generalmente, menos vista que las peliculas extranjeras" (Villegas A. \&t Alarcón S., 2017, p.369).

El desarrollo de un espacio arquitectónico especializado fue el factor fundamental que le permitió al espectáculo cinematográfico la generación de hábitos de consumo masivo en las ciudades. En el edificio para la proyección de cine fue necesario resolver, a través de la arquitectura, dos problemas en constante tensión: por una parte se requería de un espacio íntimo, un mundo interior aislado y atemporal; $y$ por otra parte era necesario que el edificio se destacara en la ciudad para lograr convocar espectadores de forma masiva. Esta doble condición espacial le permitió a los arquitectos experimentar operaciones de diseño espacial, adaptar estilos arquitectónicos y construir nuevos modelos que aportaron puntos de referencia en el paisaje urbano de las ciudades. Para una gran cantidad de habitantes en las urbes, la sala de cine se convirtió en un hito, en una nueva catedral.

En este sentido la arquitectura para la exhibición cinematográfica se puede considerar ejemplo

1. El artículo presenta algunos resultados obtenidos en el marco de la investigación titulada "Cinemas/ Capitales" Investigación adelantada a partir de 2015 con el apoyo de la Universidad de Bogotá Jorge Tadeo Lozano. La investigación se centra en el estudio de la arquitectura para la exhibición cinematográfica como elemento mediador entre el cine, como actividad cultural y de entretención, y la ciudad como soporte espacial y símbolo formal de las actividades sociales. moderno de una arquitectura global, entendida como forma de conocimiento, implicada en un sistema económico mundial y en un sistema de comunicación cada vez más sofisticado (Auge, 2005). Esta arquitectura circuló de la mano de la tecnología, de la movilidad de profesionales y de los hábitos de consumo asociados a la novedosa actividad que albergaba y que se manifestó en el desarrollo de modelos técnicos, estéticos y funcionales que hicieron uso del pensamiento arquitectónico del momento y de la experiencia de la realidad construida.

No obstante, el desarrollo de estos espacios arquitectónicos presenta desarrollos sutilmente asincrónicos. La literatura especializada en el tema muestra cómo se producía una arquitectura novedosa y de alta calidad en salas de cine de Alemania durante los años veinte (Baacke, 1982; Boeger, 1993), en Estados Unidos durante los años veinte y treinta (Naylor, 1981; Valentine, 1994), y en el Reino Unido a lo largo de los años treinta (Atwell, 1980; Gray, 1996); mientras en Colombia y específicamente en Bogotá este fenómeno se manifestó con fuerza durante los años cuarenta y cincuenta (Ávila Gómez, 2006; Montaño, 2010; Montaño Et. Al, 2011, Ávila \&t Montaño, 2017) tal y como sucedió en la mayoría 


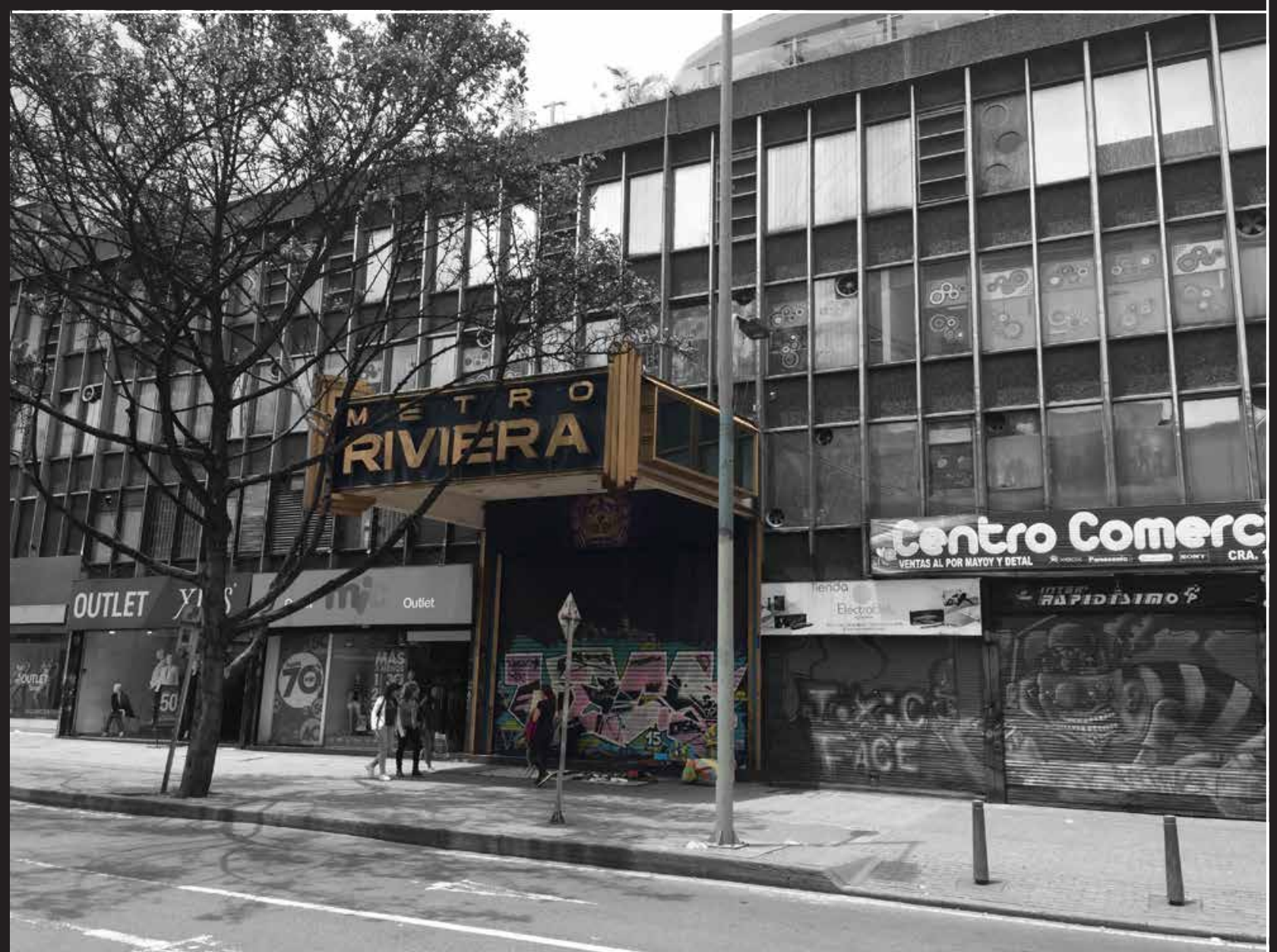

Acceso del antiguo Teatro Metro Riviera, en la localidad de Chapinero en Bogotá, de los arquitectos García y Yamhure Cía. Estado actual : 2018. (Fuente: fotografía tomada por Alfredo Montaño Bello) 


\title{
Los espacios para la exhibición de cine en Bogotá: un análisis urbano
}

\author{
Spaces for Bogota Cinema Exhibition : An Urban Analysys
}

Des architectures pour l'exploitation cinématographique à Bogotá : une analyse urbaine

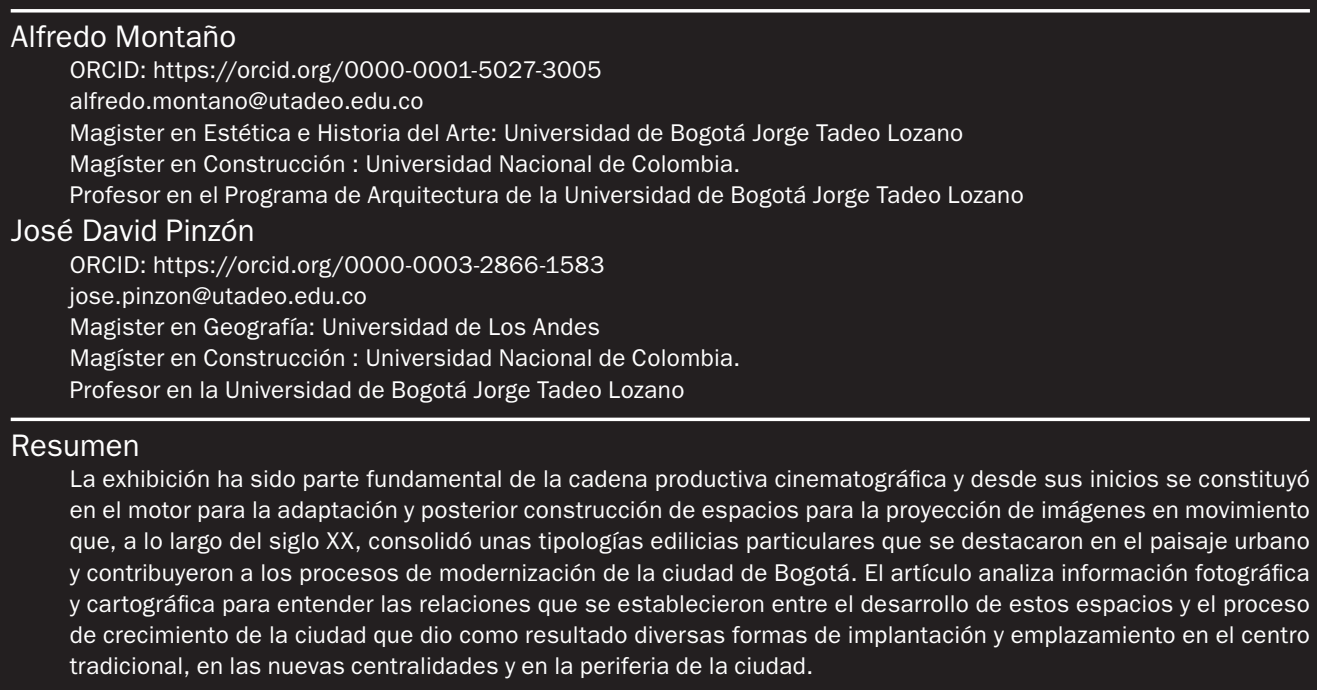

Palabras clave: arquitectura, cine, ciudad

\section{Résumé}

L'exploitation a été une partie fondamentale au sein de l'industrie cinématographique, tout en déclenchant depuis ses origines une recherche incessante visant tout d'abord à adapter, et ensuite à façonner la construction d'espaces exclusivement consacrés au cinéma. Cela a favorisé tout au long du XXe siècle l'apparition de certaines typologies architecturales non seulement remarquables dans le paysage urbain, mais aussi fondamentales en raison du rôle joué dans les processus de modernisation de la capitale colombienne, Bogotá. L'article analyse un corpus photographique et cartographique donnant des elements pour mieux comprendre les rapports existants entre le développement de ces architectures pour le cinéma, et la transformation de Bogotá, ville dont sa croissance à partir des années quarante a favorisé diverses architectures de salles implantées désormais hors du centre traditionnel : dans ses nouvelles centralités et sa banlieue.

Mots-clés: architecture, cinema, ville

Artículo de investigación

Recibido: 15 de febrero de 2017

Aprobado: 30 de mayo de 2017

Disponible en línea: 18 de junio de 2018
Abstract

Exhibiting is a fundamental part of the cinematographic production chain. From its beginnings it was the engine for the adaptation and later construction of spaces for the projection of images in movement that, throughout the XX century, consolidated some particular architectural typologies highlighted in the urban landscape that contributed to the modernization of the city of Bogotá. The article analyzes photographic and cartographic information in order to understand the relationships that were established between the development of these spaces and the growth of the city that resulted in diverse forms of implantation and location of the buildings in the traditional center, the new centralities and the periphery of the city.

Keywords: architecture, cinema, cities

doi:10.11144/Javeriana.apc31-1.eecb 
de las capitales latinoamericanas (Barrios, 1992; Salazar y Ochoa, 1997; Mejía, 2007; Méndez y García, 2010).

El presente trabajo aborda el caso de Bogotá, donde los espacios para la proyección de cine se consideran ejemplos sobresalientes de un tipo de equipamiento construido por el sector privado que se desarrolló de la mano con el crecimiento planeado, y no planeado, de la ciudad. El ejercicio de investigación realizado caracteriza el fenómeno general de la construcción de salas de cine en la ciudad con énfasis en casos específicos de tres sectores de la ciudad cuyas características reflejan lógicas urbanas y arquitectónicas particulares: el centro fundacional y el primer ensanche urbano de la ciudad, las centralidades consolidadas entre los años cuarenta y cincuenta y los sectores periféricos en permanente expansión desde los años sesenta.

Para el desarrollo de la investigación se realizó un inventario exhaustivo a través de las consultas directas al archivo de la Secretaría Distrital de Planeación y su confrontación con fuentes secundarias. Ese inventario se georreferencia mediante los datos y nomenclaturas prediales de cada época y se verifica mediante las aerofotografías históricas disponibles en el instituto geográfico Agustín Codazzi y en bases de datos de información geográfica de Bogotá. El inventario construido que sirve de base para el estudio incluye: la ubicación de las salas, la capacidad, la tipología y las fechas de inauguración y de cierre según sea el caso.

\section{Los espacios para la exhibición} de cine en Bogotá

El cinematógrafo llega a Bogotá gracias al empresario Ernesto Vieco quién realizó la primera exhibición el 1 de septiembre en 1897 en el Teatro Municipal, edificio inaugurado en 1890 y diseñado por Mariano Sanz de Santa María y Mario Lambardi. Los primeros espacios para la exhibición de cine en la ciudad de Bogotá se caracterizan por la adaptación de espacios existentes destinados originalmente para las artes escénicas, espacios públicos adaptados a través del montaje de estructuras itinerantes (Nieto y Rojas, 1992) y la adaptación de variados espacios comerciales y expositivos disponibles en la ciudad ${ }^{2}$.

Con el teatro Olympia (1912, Di Doménico Hermanos y otros), se inicia la construcción de

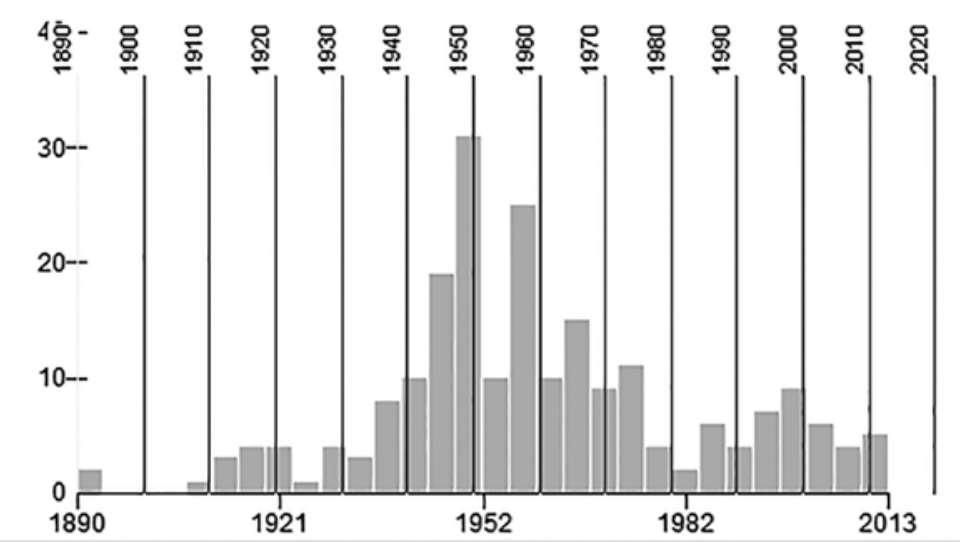

espacios cada vez más especializados para la exhibición de cine en Bogotá. Sin embargo, este edificio fue construido con las características del salón-teatro europeo que posibilitaba el uso del espacio para el montaje de múltiples escenarios para actividades de entretenimiento ${ }^{3}$ que en ocasiones complementaban la proyección de cine $\mathrm{y}$ hacían sostenible y a la vez atractivo el negocio.

La amplia demanda llevó a que otros empresarios decidieran invertir en espacios similares, dando inicio al diseño y construcción de los primeros grandes edificios para la exhibición de cine que se encargaron a importantes firmas de arquitectos, algunas de ellas extranjeras, que en su mayoría se caracterizaron por incorporar lenguajes formales propios de las vanguardias artísticas europeas. De los primeros templos se destacan por su arquitectura el teatro Faenza (1924, Juan Ernesto González Concha y otros) cuyo diseño tiene marcadas influencias del estilo Art Nouveau y los teatros San Jorge (1938, Alberto Manrique Martín y Fred T. Ley \& Co.) y Colombia (1940, Richard Eak y Germán Herrera Carrizosa \& Hermanos) cuyo diseño tiene marcadas influencias del estilo Art Deco.

Entre 1940 y 1970 se producen una serie de edificios que se identificaban en la ciudad por albergar exclusivamente la actividad de proyección y por implantarse en sitios estratégicos de la ciudad, con construcciones cada vez más funcionales que incorporaban en sus fachadas rasgos distintivos, pero cada vez más alejados de los estilos inicialmente empleados como el Art Nouveau o el Art Deco, dando lugar a una serie de experimentaciones formales que destacaban dentro del paisaje urbano y se asociaban más a lo que se conoció como el movimiento moderno en arquitectura. De estos edificios se destacan por su diseño los teatros El Cid (1951, Martínez,
Figura 1

Salas de cine en Bogotá inauguradas entre 1910 y 2013. A partir del inventario realizado se evidencia que entre 1940 y 1970 se da el mayor número de salas abiertas y en operación. Fuente:

Ávila Gómez, A. y Montaño Bello, A. (2017).

2. En Bogotá se adaptaron espacios como el Teatro Colón, el Teatro Municipal, la Imprenta Nacional, el "Pabellón de las máquinas" del Parque de la Independencia, o las Plazas de Bolívar y San Victorino.

3. Entre las principales actividades que solían adaptarse a este espacio estaban: pista de patinaje, ring de boxeo, escenario de variedades, sala de conciertos, entre otras. 
Cárdenas \&t Cia; y Suárez, Gómez, Arango Ltda.), México (1959, Obregón y Valenzuela \& Cia.), Bogotá (1965, Cuéllar, Serrano, Gómez \& Cia.) y Embajador (1969, Cristian Sarria M; y Cine Colombia). Simultáneamente, en sectores ubicados hacia la periferia de la ciudad, se seguía un proceso simultáneo de adaptación de lugares existentes para la proyección, como bodegas, iglesias, escuelas, salones comunales, entre otros, dando lugar a lo que se conoció como salas barriales incorporadas a otras tipologías edilicias.

Una variante interesante de espacio para la exhibición de cine fueron los autocines: Los Héroes (1975) y Megaoutlet (1998), promovidos por centros comerciales que quisieron en determinado momento aprovechar los parqueaderos disponibles para este fin. A partir de $1970 \mathrm{y}$ como consecuencia de avances tecnológicos que promovieron la creciente oferta de entretenimiento en casa a través de los nuevos modelos de alquiler de películas y las primeras señales internacionales de televisión, el negocio de la exhibición de cine debe adaptarse y se inicia la agrupación de varias salas en un mismo edificio a través del desarrollo de los llamados la oferta y que llevaron al posterior desarrollo de los

Tabla 1. múltiplex, los cuales compartían la infraestructura comercial y de servicio a varias salas de proyección de manera simultánea. De esta tipología edilicia se destaca el diseño del recientemente demolido Centro cinematográfico de Bogotá (1975, L. y L.H. Forero, Rodrigo Arboleda H. y Fajardo Vélez \& Cia.) el cual contaba con las primeras escaleras eléctricas instaladas en un cinema. Estos modelos de agrupación se dieron simultáneamente con el fenómeno de incorporación de las salas de cine a las dinámicas de los centros comerciales lo que dio comienzo a la manera como hoy se disfruta el cine de manera masiva. Ejemplos pioneros en esta línea fueron los cinemas A y B del centro comercial Unicentro (1976, Pedro Gómez \& Cia.) y la sala del centro comercial Terraza Pasteur (1989, Piedad Burgos F.). En síntesis, las tipologías de espacios para la exhibición de cine desarrolladas a lo largo del siglo XX en Bogotá se pueden caracterizar a través de algunos ejemplos expuestos en la Tabla 1.

\section{LAS SALAS DE CINE Y EL CRECIMIENTO DE LA CIUDAD}

El desarrollo de las salas de cine va de la mano con el crecimiento de la ciudad y configura distintas tipologías edilicias y distintos fenómenos de

\begin{tabular}{|c|c|c|}
\hline Tipología & Característica & Algunos ejemplos en Bogotá \\
\hline Espacios Adaptados & $\begin{array}{l}\text { Adaptación de espacios para las artes escénicas, espacios } \\
\text { públicos a través del montaje de estructuras itinerantes } \\
\text { y la adaptación de espacios comerciales y expositivos } \\
\text { disponibles. }\end{array}$ & Teatro Municipal (1897) \\
\hline $\begin{array}{l}\text { Primeros salones de } \\
\text { proyección }\end{array}$ & $\begin{array}{l}\text { Edificios que incorporan lenguajes formales propios de } \\
\text { las vanguardias artísticas europeas y se convierten en } \\
\text { referentes de modernización en la ciudad. }\end{array}$ & $\begin{array}{l}\text { Salón Olympia (1912), Salón } \\
\text { Luz - Faenza (1924), San } \\
\text { Jorge (1938) y Colombia } \\
(1940)\end{array}$ \\
\hline Cinemas & $\begin{array}{l}\text { Edificios que albergan exclusivamente la actividad } \\
\text { de proyección y se implantan en sitios estratégicos, } \\
\text { con construcciones cada vez más funcionales que } \\
\text { incorporaban en sus fachadas experimentaciones } \\
\text { formales que destacaban dentro del paisaje urbano y que } \\
\text { se asociaban a lo que se conoció como el movimiento } \\
\text { moderno en arquitectura. }\end{array}$ & $\begin{array}{l}\text { El Dorado (1948), El Cid } \\
\text { (1951), México (1959), } \\
\text { Bogotá (1965) y Embajador } \\
\text { (1969). }\end{array}$ \\
\hline Salas de cine & $\begin{array}{l}\text { Espacios de proyección que forman parte de otras } \\
\text { tipologías arquitectónicas como edificios de vivienda } \\
\text { u oficinas y que no se reconocen fácilmente por su } \\
\text { protagonismo en la ciudad. }\end{array}$ & $\begin{array}{l}\text { Novedades (1957), } \\
\text { Radioteatro Sutatenza } \\
\text { (1958), La Carrera (1960). }\end{array}$ \\
\hline Autocine & $\begin{array}{l}\text { Espacio de proyección al aire libre que permite observar } \\
\text { las imágenes en movimiento desde la comodidad de un } \\
\text { vehículo. }\end{array}$ & $\begin{array}{l}\text { Autocine los Héroes (1975) } \\
\text { Autocine Megaoutlet (1998) }\end{array}$ \\
\hline Multipantallas & $\begin{array}{l}\text { Edificio que agrupa varias salas pero cada una de ellas } \\
\text { cuenta con infraestructura independiente de servicios y } \\
\text { de proyección. }\end{array}$ & $\begin{array}{l}\text { Centro Cinematográfico } \\
\text { (1976) }\end{array}$ \\
\hline Múltiplex & $\begin{array}{l}\text { Edificio que agrupa múltiples salas y que comparte la } \\
\text { infraestructura de servicios y de proyección. }\end{array}$ & $\begin{array}{l}\text { Nuevo Multiplex Embajador } \\
\text { (2003). }\end{array}$ \\
\hline $\begin{array}{l}\text { Salas Múltiplex en } \\
\text { centros comerciales }\end{array}$ & $\begin{array}{l}\text { Salas tipo multiplex que forman parte de locales dentro } \\
\text { de centros comerciales. }\end{array}$ & Salas A y B Unicentro (1976) \\
\hline
\end{tabular}




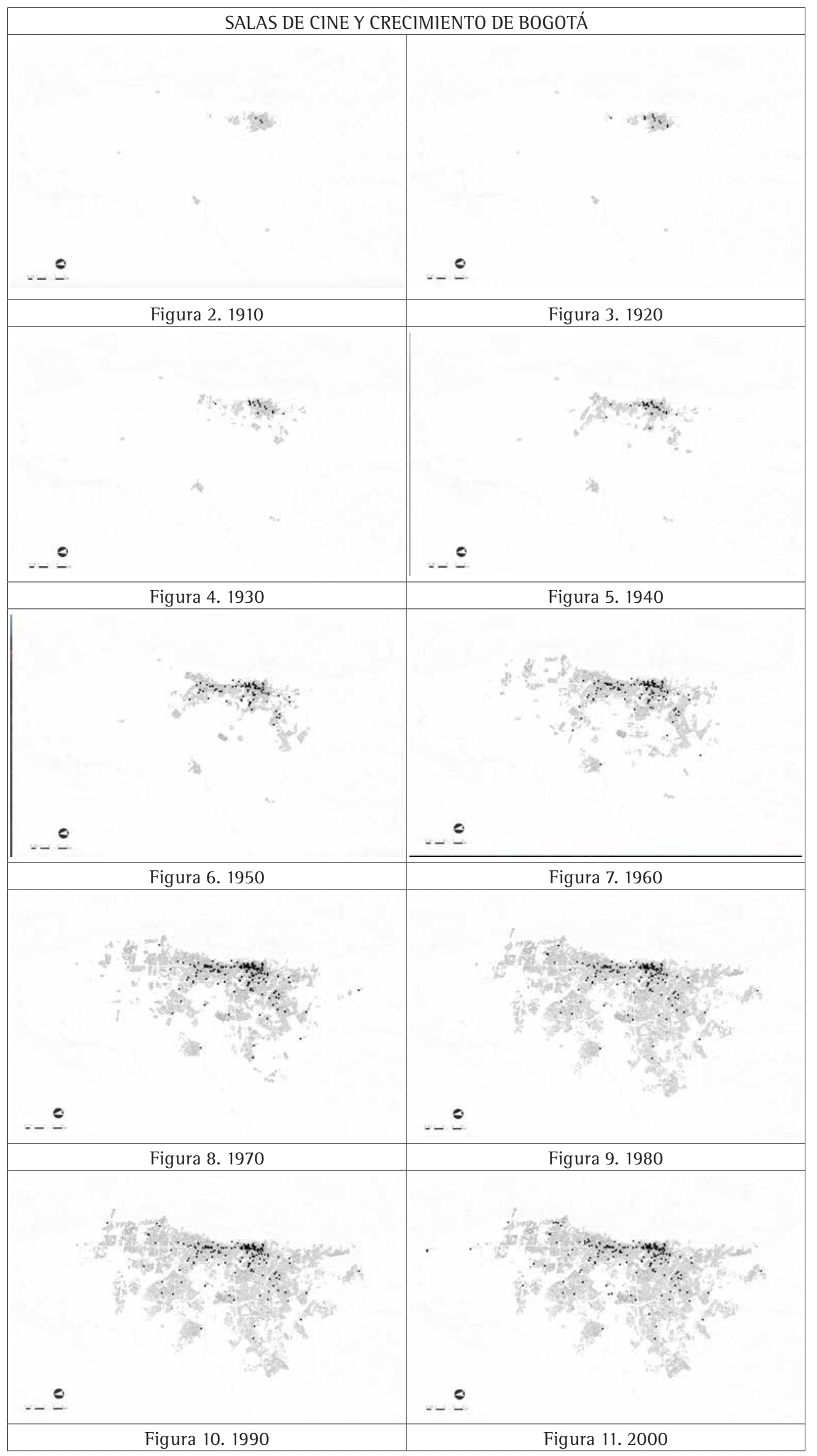

Figuras 3 a 11.

Superposición (por décadas) de la ubicación de las salas de cine a los planos de crecimiento de Bogota durante todo el siglo XX.

Fuente:

Montaño y Pinzón. 
agrupación particulares. Es posible analizarlos al superponer la ubicación de las salas de cine a los planos de crecimiento de la ciudad durante el siglo $X X$. Se evidencia como las salas de cine fueron consolidando clusters, ejes y nuevas centralidades caracterizadas por ser espacios de encuentro alrededor de la cultura y el entretenimiento y símbolos de modernidad en la ciudad (Tabla 2).

Hasta 1910 (Figura 2), Bogotá fue una ciudad compacta, que vivía un proceso de densificación continuo para absorber los incrementos demográficos sin extender significativamente su área urbana. En este periodo se adaptan los primeros espacios y se construye la primera gran sala de proyección el Salón Olympia (1912). Posteriormente en los años 20 las salas tomaron mayor protagonismo en la ciudad y su función generó actividades particulares de encuentro y vitalidad urbana (Fig. 3). Estos edificios se conocen comúnmente como los primeros salones de proyección y aparecen justamente cuando la estructura decimonónica cerrada de la ciudad se transforma, al conectar la antigua ciudad compacta con los primeros barrios residenciales localizados en los suburbios del norte, del sur y del occidente.

En las cuatro primeras décadas del siglo XX (Figuras 2, 3, 4 y 5) Bogotá casi cuadruplicar su tamaño, y en este periodo se construyeron los primeros cinemas en el centro tradicional de la ciudad caracterizadas por su gran tamaño y por adaptar estilos propios de las vanguardias europeas. A partir de 1940 (Figura 5), y principalmente con posterioridad al llamado Bogotazo ${ }^{4}$, se presenta una gran expansión de la ciudad, jalonada entre otros aspectos por los procesos migratorios derivados de la compleja situación política y social del país. Como consecuencia se incrementa una notoria segregación espacial con sectores residenciales para familias de estratos altos que en general se desarrollan hacia el norte de la ciudad, sobre las vías principales como las carreras séptima y trece y otros de clase obrera que se desarrollan hacia el occidente y el sur en forma de barrios informales de desarrollo progresivo y

parcial de algunos sectores en varias ciudades del país.

Tabla 2.

Resumen de algunas referencias a las salas de cine en estudios $y$ documentos oficiales de planeación urbana. Fuente:

Avila Gómez, A. y Montaño Bello, A. (2017).

\begin{tabular}{|c|c|}
\hline Documento & Aspectos tratados frente a las salas de cine. \\
\hline $\begin{array}{l}\text { Decreto } 103 \text { de } 1940 . \\
\text { Reglamento General de } \\
\text { Espectáculos. }\end{array}$ & $\begin{array}{l}\text { Se especifican las normas que debían cumplir las edificaciones para espectáculos, } \\
\text { prestando especial atención al caso de las salas de cine (Escenario y accesorios, } \\
\text { Casilla de proyección, Puertas, Silletas y pasillos interiores, Escaleras, Taquillas, } \\
\text { Servicios sanitarios, Alumbrado e instalaciones eléctricas, Medidas de seguridad } \\
\text { contra incendio). }\end{array}$ \\
\hline $\begin{array}{l}\text { Acuerdo } 21 \text { de } 1944 . \\
\text { Plan Soto-Bateman }\end{array}$ & $\begin{array}{l}\text { Capítulo IV, artículo } 38 \text { señala que en la zonas estrictamente residenciales (formadas } \\
\text { por las urbanizaciones nuevas y por los terrenos no urbanizados que deben } \\
\text { destinarse exclusivamente a construcciones para habitación) “... solo se permitirán } \\
\text { edificaciones para el comercio local, edificios para el culto religioso, clínicas, teatros } \\
\text { y establecimientos docentes destinados a tal fin en manzanas completas o en predios } \\
\text { de gran extensión (...)" } \\
\text { Se establecen además normas tendientes a regular las innovaciones materiales que } \\
\text { rápidamente comenzaban a redefinir el paisaje urbano bogotano -especialmente en } \\
\text { la noche, con el uso creciente de dispositivos luminosos- contenian disposiciones } \\
\text { expresas sobre los avisos y anuncios desplegados en las fachadas comerciales, lo cual } \\
\text { tendría sin duda un impacto directo en el diseño de las fachadas de cinemas. }\end{array}$ \\
\hline $\begin{array}{l}\text { Decreto } 185 \text { de } 1951 \\
\text { Por el cual se adoptó el } \\
\text { Plan Piloto formulado } \\
\text { por Le Corbusier, y se } \\
\text { dictaron normas sobre } \\
\text { urbanismo }\end{array}$ & $\begin{array}{l}\text { En el Plan Regulador de Wiener y Sert, encontramos el apartado titulado "Área } \\
\text { de Comercio Central”: Se encontrarán en este centro comercial los comercios de } \\
\text { lujo, grandes almacenes, almacenes de cinco y diez (del tipo de los almacenes Tía y } \\
\text { Ley), cafés, cinematógrafos, teatros, cabarets, salas de exposiciones, restaurantes, } \\
\text { pequeñas y grandes tiendas de todo género. Será este el centro de más animación } \\
\text { representativo de una gran ciudad moderna. Establece un nexo entre el área cívico- } \\
\text { administrativa de la Plaza de Bolívar y el grupo de edificios culturales-recreativos y } \\
\text { turísticos del Parque de la lndependencia." }\end{array}$ \\
\hline $\begin{array}{l}\text { Temas Urbanos } \\
\text { de Bogotá, } 1962 . \\
\text { Publicación del } \\
\text { Departamento } \\
\text { Administrativo de } \\
\text { Planificación Distrital }\end{array}$ & $\begin{array}{l}\text { En la sección titulada "Cinematógrafos", describe la actualidad de dichos } \\
\text { equipamientos en la capital: según este documento, en el Distrito Especial de Bogotá } \\
\text { funcionaban en aquel momento un total de } 80 \text { salas, y se citan algunas cifras. } \\
\text { Según dicho boletín, en 1961 asistieron a las salas de cine bogotanas un total de } \\
\text { 19'802.298 espectadores: 19'296.889 a los cinemas del perímetro urbano, y 505.409 } \\
\text { a los cinemas de los municipios anexados, lo cual representaba de lejos "la mayor } \\
\text { distracción de los habitantes de la capital de la República". }\end{array}$ \\
\hline $\begin{array}{l}\text { Estudios e informes de } \\
\text { una ciudad en marcha, } \\
\text { 1967-1969. Tomo V1l } \\
\text { y VIll. }\end{array}$ & $\begin{array}{l}\text { Se describe el "Plan Muelas" -plan de adquisición y demolición de inmuebles que } \\
\text { obstaculizaban la continuidad de algunas vías ampliadas-, en las cuales se aprecian } \\
\text { cinemas que sufrieron cambios importantes en su arquitectura exterior luego de } \\
\text { dicha intervención: por ejemplo, el Teatro Atenas y el Cine Teatro Novedades. En el } \\
\text { tomo V1Il aparece el proyecto para el Teatro Distrital, proyecto que reemplazaría el } \\
\text { antiguo Teatro Municipal pero que nunca fue construido. }\end{array}$ \\
\hline
\end{tabular}


sectores de autoconstrucción, o barrios formales desarrollados por el estado o por proyectos de urbanización privada, ambos fenómenos en tensión con el centro tradicional. Esta dinámica sirvió para consolidar el barrio como la unidad de expansión urbana, con lo cual se cambió la fisonomía de Bogotá hacia un modelo radial. No obstante, se mantuvieron las actividades primarias y los equipamientos urbanos concentrados en la ciudad heredada del siglo XIX.

El paso de una forma lineal al modelo radial de ciudad corresponde con una primera etapa de modernización de Bogotá, en la cual se inicia un mayor interés por lo público en la ciudad, representado no solamente por los espacios y equipamientos de gran escala, sino además por la aparición de normas e instituciones que intentaron enmarcar y organizar el crecimiento físico de la capital. Estos primeros intentos de controlar y regularizar el crecimiento urbano también tuvieron un reflejo en la aparición de normas urbanísticas aplicables a las salas de cine. A continuación, se hace un resumen de las referencias a las salas de cine en estudios y documentos oficiales de planeación urbana (Tabla 3).

A partir de la década de los años 50 la ciudad inició un crecimiento exponencial de su población, pasando de unos 700.000 habitantes en 1951 a unos 1.600.000 en 1964. Este crecimiento implicó que los planes de control y planeación urbana, que en un primer momento consistieron en acciones y proyectos específicos, pasaran a la idea de proyectos de planificación más generales, con el Plan Piloto de Le Corbusier (1950) y el Plan Regulador de Town Planning
Associates (1953). Desde 1950 a 1970 (Figuras 6, 7 y 8), se destaca la aparición de áreas residenciales conectadas con la ciudad central sin generar un proceso claro de compactación entre ellas, a pesar de los planes y normas existentes. En este periodo los empresarios de circuitos y comerciantes particulares interesados en el negocio del cine, se aventuraron a construir masivamente salas de cine en zonas intermedias aún no consolidadas, copiando ejemplos construidos en Europa según el modelo funcionalista alemán (Cinema Universum, Mendelsohn) y el modelo de arquitectura corporativa impuesto por los cines a través de circuitos como el británico Odeón durante los años treinta.

Para la década de 1980 las dinámicas precedentes perfilaron la ciudad como una estructura policéntrica (Figura 9), pasando del desarrollo de barrios monofuncionales, que no poseían equipamientos y dependían enteramente de la oferta de la ciudad central, a la consolidación de dos nuevas formas de crecimiento urbano, inspiradas por los principios urbanísticos pregonados por la arquitectura moderna: los barrios de viviendas en serie y las torres de vivienda multifamiliares, promovidas inicialmente por entidades estatales y posteriormente por la empresa privada.

Proyectos pioneros en este sentido son el Centro Urbano Antonio Nariño (1952-1958) y Pablo VI - primera etapa (1967), que reproducían dichos conceptos de barrios integrales que incluian salas de cine cuyo diseño se alejaba finalmente de las tendencias eclécticas, del estilo Art deco y de los modelos europeos, para adoptar un lenguaje formal más cercano al Estilo Internacional.
Figura 12.

Superposición de las salas de cine al crecimiento urbano de Bogotá. El color amarillo corresponde a los núcleos fundacionales y a medida que avanza hacia el color rojo se representan los desarrollos urbanos mas recientes.

Fuente: Montaño y Pinzón.

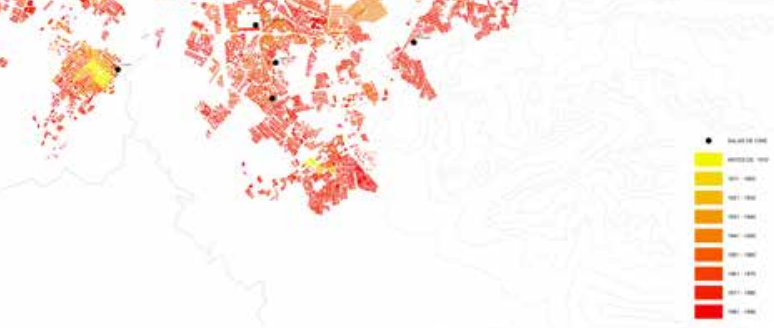


Entre 1990 y la primera década del siglo XXI (Figuras 10 y 11) la estructura del negocio de las salas de cine cambia y se da con mayor fuerza el fenómeno de los múltiplex, como complejos de gran capacidad que se ubican en centralidades específicas de la ciudad bajo las dinámicas propias de los centros comerciales. A manera de sintesis en la figura 12 se aprecia la superposición de las salas de cine al crecimiento urbano de Bogotá.

En la figura 13 se destaca la densidad de salas que se configura en el centro tradicional, una segunda concentración de salas en el sector norte sobre el sector de chapinero y las múltiples centralidades en las periferias con equipamientos concentrados y capacidades superiores a las 1000 sillas y algunas pocas salas de cine barriales con capacidades entre las 300 y las 600 sillas.
Se pueden evidenciar en Bogotá tres fenómenos urbanos particulares alrededor de la ubicación geográfica de las salas de cine. El primero es la configuración de un importante cluster de cines en el centro de la ciudad, a partir de la consolidación de un centro con actividades de comercio y servicios. El segundo es la configuración de un corredor cultural en el sector norte de la ciudad conocido como el sector de Chapinero, siguiendo las zonas de vivienda de estratos altos y el tercero es la ordenación de sectores a partir de equipamientos que forman parte de los núcleos públicos locales en los barrios, principalmente los de desarrollo formal o estatal, como es el caso del barrio La Castellana (1965) o las Unidades habitacionales de Pablo VI (1967) o el Centro Urbano Antonio Nariño (1952-1958). En la figura 14 se observa la ubicación de los tres fenómenos descritos que se amplían en las figuras 15, 16 y 17.
Figura 13. Mapa general de localización de las salas y representación de las capacidades instaladas.

Montaño y $\mathrm{Pi}$

Fuente:

Figura 14. Mapa general de localización de las salas y ubicación del cluster en el centro tradicional

(1), el eje cultural en

el sector norte (2) y algunas centralidades barriales como el sector de la castellana 3.

Fuente:

Montaño y Pinzón.
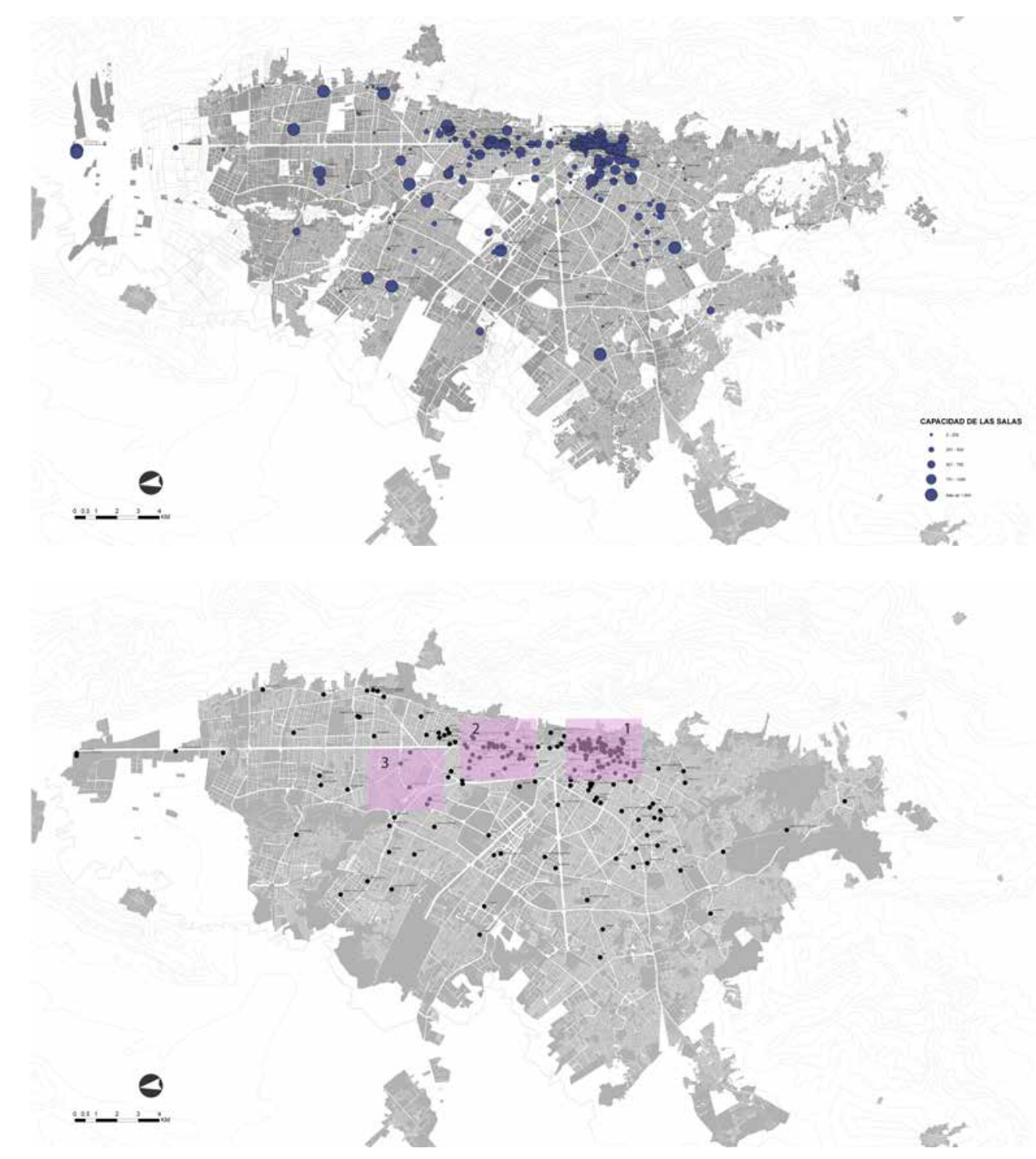


\section{Conclusiones}

Los espacios para la exhibición de cine fueron agente y efecto del cambio urbanístico de Bogotá y esto se evidencia a través de los diferentes fe- nómenos que se consolidaron en relación a estos equipamientos a lo largo del siglo XX. El primero es el cluster de salas desarrollado durante las primeras cuatro décadas en el centro tradicional, lo que generó la consolidación de este sector como

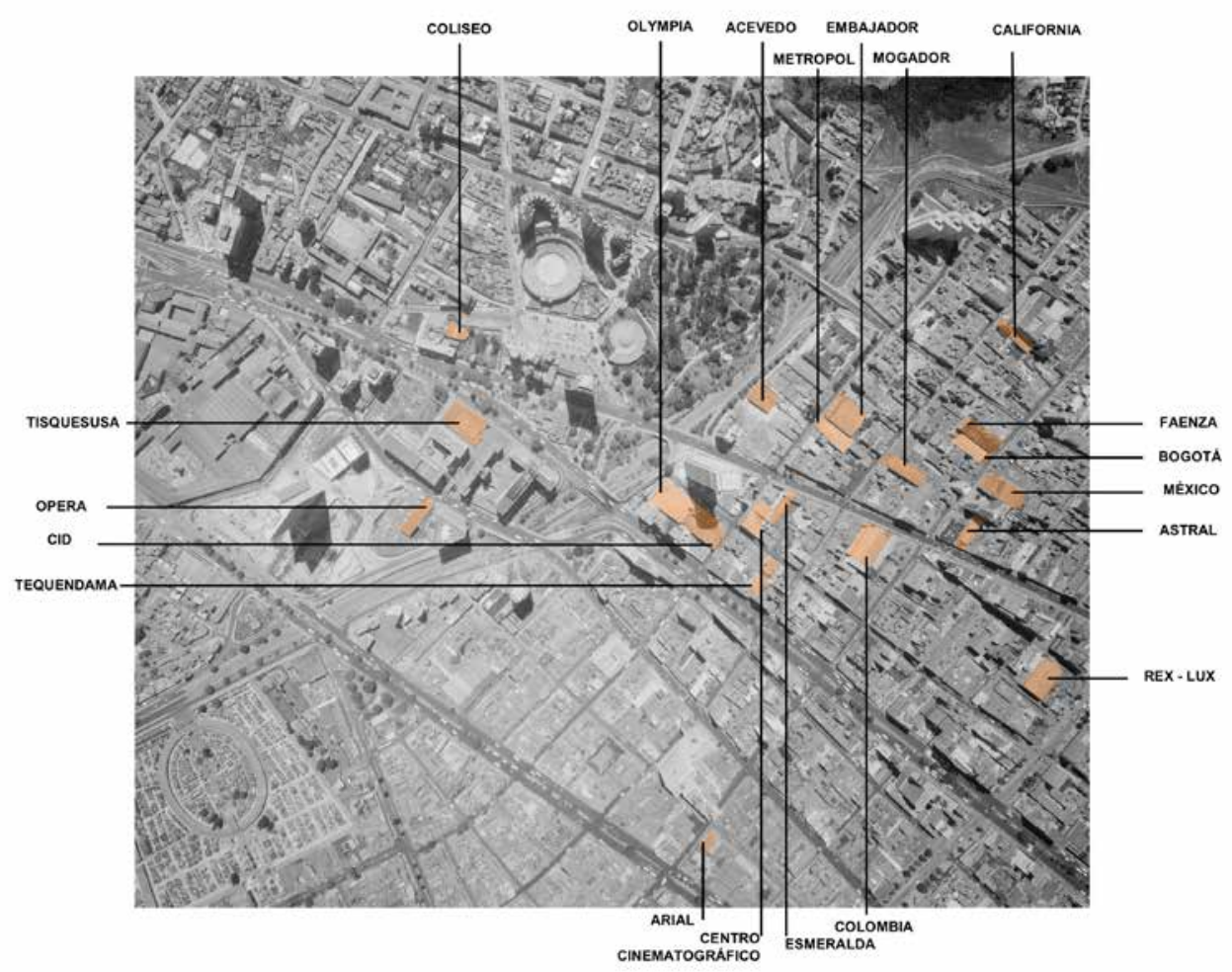

Figura 15.

Ubicación de salas de cine en aerofotografía del centro de

Bogotá, 1977

Fuente:

Aerofotografía del Instituto Geográfico

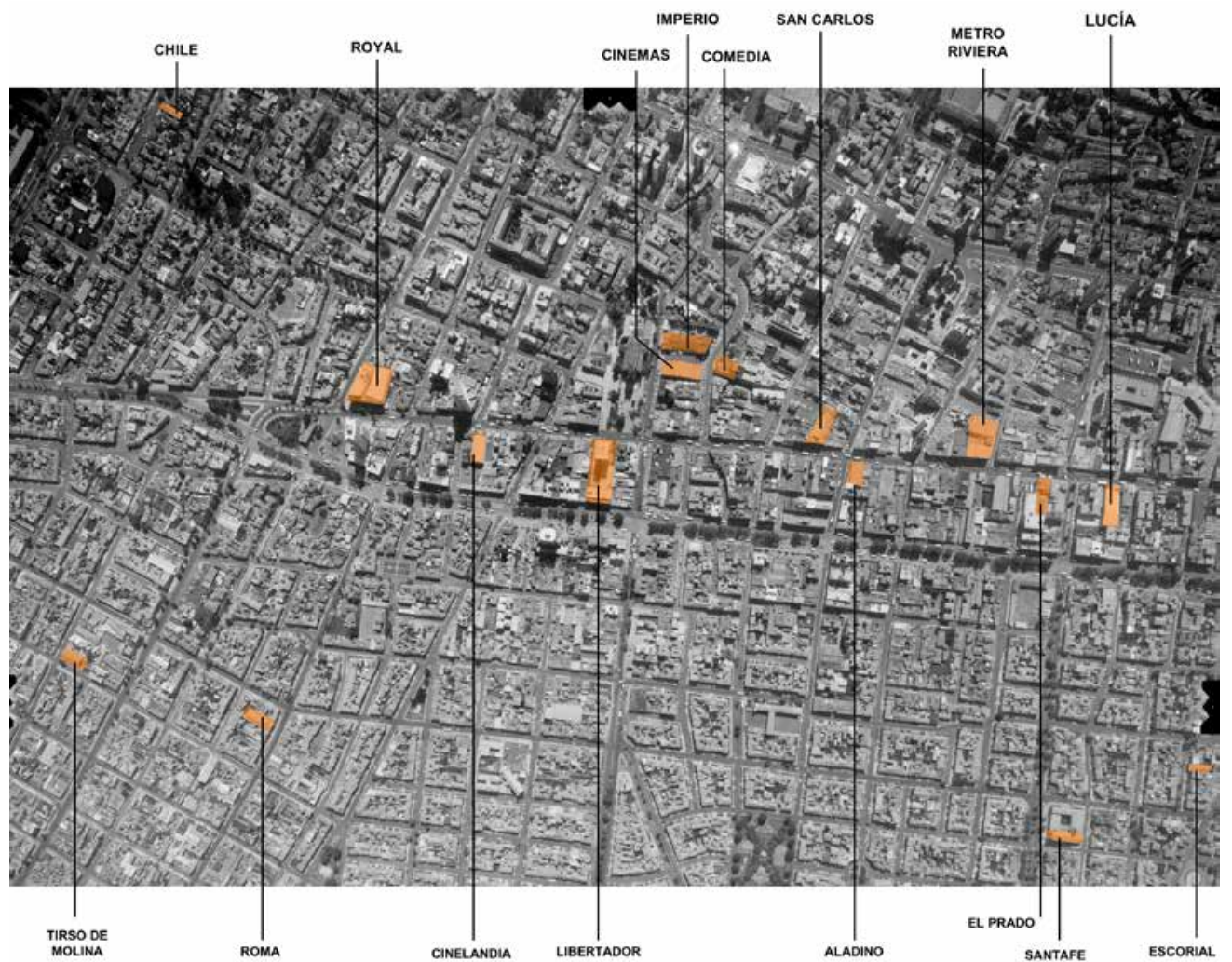

Agustín Codazzi - 1GAC. Análisis elaborado por: Avila Gómez, A. y Montaño Bello, A. (2017).

Figura 16.

Ubicación de salas de cine en aerofotografía de Chapinero, al norte de Bogotá, 1977.

Fuente:

Aerofotografía del Instituto Geográfico Agustín Codazzi - 1GAC. Análisis elaborado por: Avila Gómez, A. y Montaño Bello, A. (2017). 


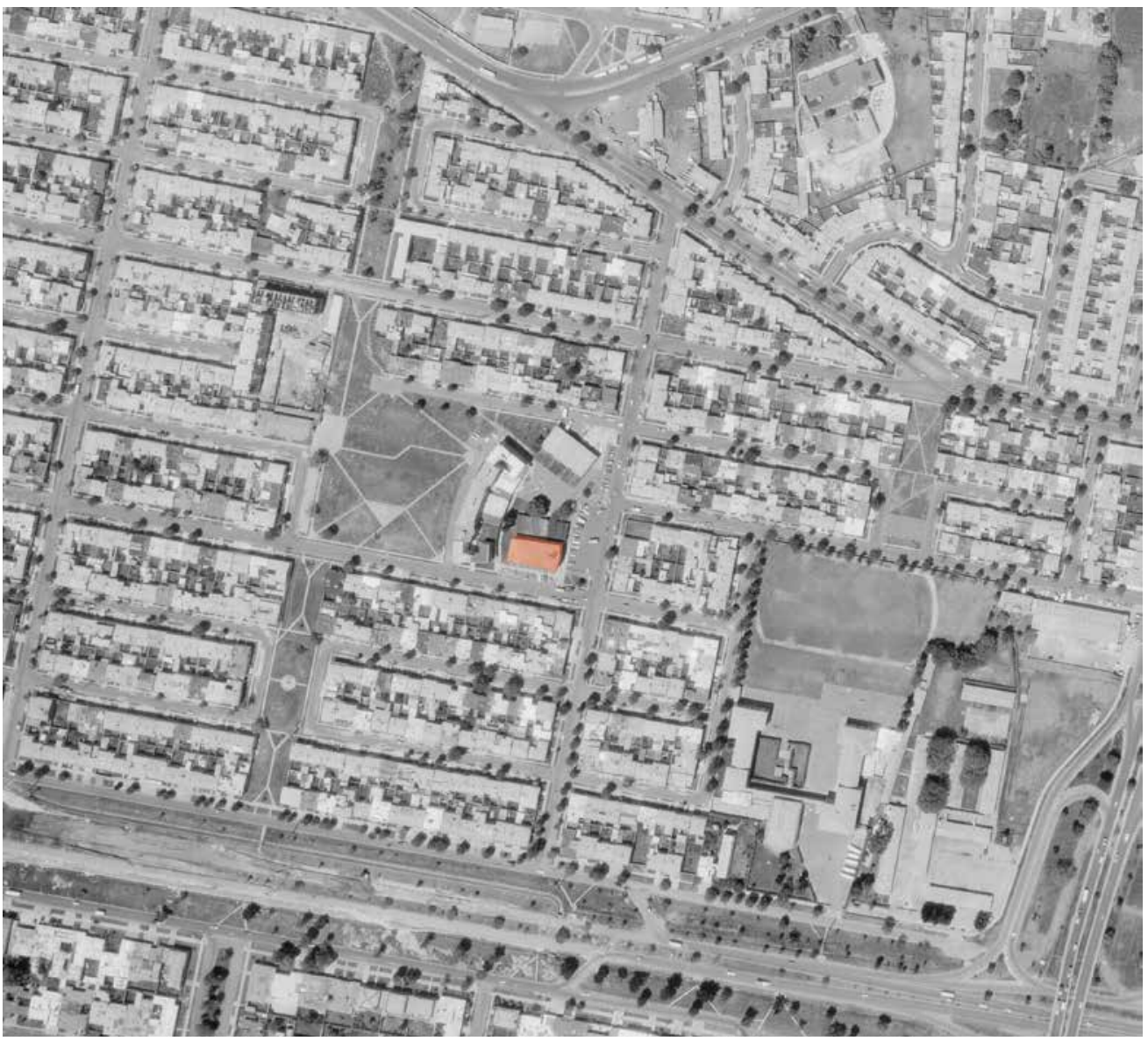

polo cultural y símbolo de modernización de la ciudad y del país. El segundo es el eje cultural y comercial del sector de chapinero consolidado a lado y lado de la carrera 13 y que se desarrolló principalmente entre 1950 y 1980, fenómeno que generó una vocación de entretenimiento en el sector ligado al ritual de ir de compras a través de una calle comercial. El tercer fenómeno lo caracteriza el servir de equipamiento complementario en la configuración de barrios y centralidades en sectores periféricos de la ciudad, tanto en la versión de sala barrial o unidad vecinal, como también al ser complemento de los centros comerciales, fenómeno que se dio al final de la segunda mitad del siglo XX.

El recorrido por los espacios para la exhibición cinematográfica comienza por la adaptación de los dispositivos técnicos de proyección a lugares de encuentro en la ciudad, pues además que no se contaba con espacios diseñados para tal actividad se procuraba aprovechar los espacios públicos para publicitar la novedad técnica que arribaba como nueva alternativa de entretenimiento. Posterior a este inicio se da el desarrollo progresivo de distintas tipologías arquitectóni- cas, identificadas en la investigación a partir de ejemplos concretos que condensan el encuentro de un pensamiento arquitectónico de cada época con la práctica constructiva en la realidad. Estos espacios arquitectónicos fueron desarrollados de la mano con la evolución técnica de la exhibición y los modos de consumo del cine que eran a su vez reflejo de las condiciones socioeconómicas y culturales de una población que habitaba una ciudad en constante desarrollo. Esta complejidad configura un importante objeto de estudio con múltiples valores que como tipología edilicia novedosa permitió la experimentación técnica, estética y funcional, producto de procesos económicos y sociales particulares pero a la vez conectados con unas lógicas culturales y de mercado internacionales que le conceden un status global a este fenómeno y que posibilita su legado hasta nuestros días.

Frente a este último aspecto, estos edificios junto con su contexto urbano configuran hoy por hoy un fenómeno problemático de intervención y de gestión para su sostenibilidad como patrimonio, sin embargo, su presencia real y física rememoran el ritual de ir al cine y permiten que 
el imaginario colectivo haga presente el pasado gracias al renovado interés que despierta la investigación alrededor de estos edificios singulares y en general frente a la relación entre la industria del cine y la vida en la ciudad.

\section{Referencias}

Alcaldía Mayor de Bogotá. (1940). Decreto 103 de 1940. Reglamento General de Espectáculos. Bogotá: Municipio de Bogotá.

Álfaro Salazar, F. \&t Ochoa Vega, A. (1997). Espacios distantes...aún vivos. Las salas cinematográficas de la Ciudad de México. México D.F.: Universidad Autónoma MetropolitanaUnidad Xochimilco.

Anales de lngeniería (1953). Decreto 185 de 5 de abril de 1951, vol. LVIIl 640 (pp. 108-123). Bogotá: Sociedad Colombiana de Ingenieros.

Anales de Ingeniería (1953). El Plan Regulador es base indispensable para ordenar el crecimiento de Bogotá: por el lng. Julio Carvajal, vol. LVIII, 640 (p. 5). Bogotá: Sociedad Colombiana de lngenieros.

Anales de Ingeniería (1953). El Plan Regulador. Memoria de los arquitectos urbanistas Wiener y Sert. vol. LVIIl, 640 (pp. 7-107). Bogotá: Sociedad Colombiana de Ingenieros.

Atwell, D. (1980). Cathedrals of the movies. A History of British Cinemas and Their Audiences. Londres: The Architectural Press.

Auge, M. (2005). Global / Local, Universal / Particular. Barcelona: Fundación CIDOB

Ávila Gómez, A. (2006). Salas de cine. Bogotá: Archivo de Bogotá.

Ávila Gómez, A. \&t Montaño Bello, A. (2015). Salas de cine en Bogotá, 1897-1940: la arquitectura como símbolo de modernización del espacio urbano. Les Cahiers ALHIM - Amérique Latine Histoire et Mémoire (París), 29, 111-136.

Avila Gómez, A. \&t Montaño Bello, A. (2017). Arquitecturas para el cine en Bogotá: centro, centralidades y periferia (1940 - 1980). Actas Seminario internacional de investigación en urbanismo - IX Seminario Internacional de Investigación en Urbanismo, junio de 2017, Barcelona : Departament d'Urbanisme i Ordenació del Territori. Universitat Politècnica de Catalunya. Recuperado de https://upcommons.upc.edu/handle/2117/107595
Baacke, R-P. (1982). Lichtspielhausarchitektur in Deutschland, von der Schaubude bis zum Kinopalast. Berlin: Verlag Frölich \& Kaufmann.

Barrios, G. (1992). Inventario del olvido. La sala de cine y la transformación metropolitana de Caracas. Caracas: Fundación Cinemateca Nacional.

Boeger, P. (1993). Architektur der Lichtspieltheater in Berlin. Bauten und Projekte, 1919-1930. Berlin : Verlag Willmuth Arenhövel.

Departamento Administrativo de Planificación Distrital Bogotá. (1962). Temas urbanos de Bogotá. Bogotá: Imprenta Distrital de Bogotá.

Gray, R. (2011/1996). Cinemas in Britain. A History of Cinema Architecture. Londres: Lund Humphries Publishers.

Mejía Ticona, V. (2007). llusiones a oscuras. Cines en Lima: carpas, grandes salas y multicines, 1897-2007. Lima: Centro Cultural de España en Lima.

Méndez, P, García Falcó, M. (2010). Cines de Buenos Aires : patrimonio del siglo XX. Buenos Aires: CEDODAL - Centro de Docuentación de Arte y Arquitectura Latinoamericana.

Montaño Bello, A, Rojas Farías, R \& Solarte Pinta, E. (2011). La arquitectura del teatro. Tipologías de teatro en el centro de Bogotá. Bogotá: Editorial Universidad de Bogotá Jorge Tadeo Lozano.

Montaño Bello, A. (2010). Arquitectura para la exhibición de cine en el centro de Bogotá. Revista de Arquitectura (Bogotá), 12(1), 79-87.

Naylor, D. (1981). American Picture Palaces: The Architecture of Fantasy. New York: Van Nostrand Reinhold.

Nieto, J. \& Rojas, D. (1992). Tiempos del Olympia. Bogotá: Fundación Patrimonio Fílmico Colombiano.

Secretaría de Obras Públicas. (1944). Acuerdo número 21 de 1944. Disposiciones sobre obras públicas y particulares. Bogotá: Municipio de Bogotá.

Valentine, M. (1994). The Show Starts On the Sidewalk. An Architectural History of the Movie Theatre. New Haven: Yale University Press.

Villegas, A. \&t Alarcón, S. (2017). Historiografía del Cine Colombiano. 1974 - 2015. HISTOReLo. Revista de historia regional y local, 9(18), 344-382. https://doi.org/10.15446/historelo. v9n18.58785 